\title{
A Phenomenological Theory for Ductility Loss of Neutron Irradiated Iron and Iron Alloys*
}

\section{By Naohiro IGATA** and Katsutoshi WATANABE***}

The neutron irradiation induced embrittlement is one of the most important problems in nuclear structural materials. ${ }^{1-3)}$ The authors ${ }^{4-6)}$ have been investigating about the loss of ductility due to irradiation, and clarified the relation between uniform elongation and work hardening coefficient and also the effects of alloying elements on the ductility after irradiation.

The objective of this study is to clarify the loss of total elongation including both uniform elongation and post-uniform elongation of neutron irradiated iron and iron alloys.

The chemical compositions of used materials were Fe-70wt.ppmN(Fe-N), Fe-0.5wt.\%Mo-70wt.ppmN(Fe-Mo-N) and $\mathrm{Fe}-0.2 \mathrm{wt} . \% \mathrm{Cu}-70$ wt.ppmN(Fe-Cu$\mathrm{N})$. The specimen for tensile testing was cut out to the size $1 \times 3 \times 24 \mathrm{~mm}$ (parallel part). The specimens were annealed at $800{ }^{\circ} \mathrm{G}$ for $1 \mathrm{hr}$ in vacuum of $1 \times 10^{-5}$ torr, and subsequently quenched into water. The irradiation was carried out at JRR-2 to a fluence of $3 \times 10^{19} \mathrm{n} / \mathrm{cm}^{2}(\mathrm{E}>1 \mathrm{MeV})$. The irradiation temperature was about $60^{\circ} \mathrm{C}$. Tensile tests were performed at room temperature by using an Instron type testing machine. The strain rate was at the range from $3.47 \times 10^{-4}$ to $1.39 \times 10^{-3} \mathrm{sec}^{-1}$.

The general relation between true stress $\sigma$ and true strain $\varepsilon$, at constant temperature and strain rate, can be expressed by the next equation.

$$
\sigma=A \varepsilon^{n}
$$

where, $A$ : materials constant

$n$ : work hardening coefficient.

From the Eq. (1), the work hardening coefficient can be expressed as follows.

$$
n=\frac{d \log \sigma}{d \log \varepsilon}
$$

As generally accepted the strain at load maximum $\varepsilon_{u}$ is equal to $n$.

Figure 1 shows the relation between $\varepsilon_{u}$ and $n$ for both unirradiated and irradiated iron and iron alloys. After irradiation, $\varepsilon_{u}$ decreases with decreasing $n$. As for the strain rate dependence of flow stress, the relation can be expressed as the next equation.

$$
\sigma=K \dot{\varepsilon}^{m}
$$

where, $\dot{\varepsilon}:$ strain rate

$\kappa$ : materials constant

$m$ : strain rate sensitivity coefficient.
From the Eq. (3), the strain rate sensitivity coefficient can be expressed as follows.

$$
m=\frac{d \log \sigma}{d \log \dot{\varepsilon}}
$$

This $m$ value is considered to be controlling factor for necking strain. Since it is very difficult to measure the local ductility in irradiated materials, the conventional total strain $\varepsilon_{t}$ is taken as shown in the next equation.

$$
\varepsilon_{t}=\ln \frac{l_{f}}{l_{0}}
$$

where, $l_{0}$ : original gauge length

$l_{f}$ : current length after fracture including both uniform strain and local necking strain.

And post-uniform strain $\varepsilon_{l}$ was taken as $\varepsilon_{t}-\varepsilon_{u}$.

Figure 2 shows the relation between local necking strain $\varepsilon_{t}-\varepsilon_{u}\left(=\varepsilon_{l}\right)$ and $m$ value. The linear relation between $\varepsilon_{l}$ and $m$ values is obtained. Therefore, total strain as defined in the Eq. (5) can be expressed as the next equation phenomenologically.

$$
\begin{aligned}
\varepsilon_{t} & =\varepsilon_{u}+\varepsilon_{l} \\
& =C n+D m
\end{aligned}
$$

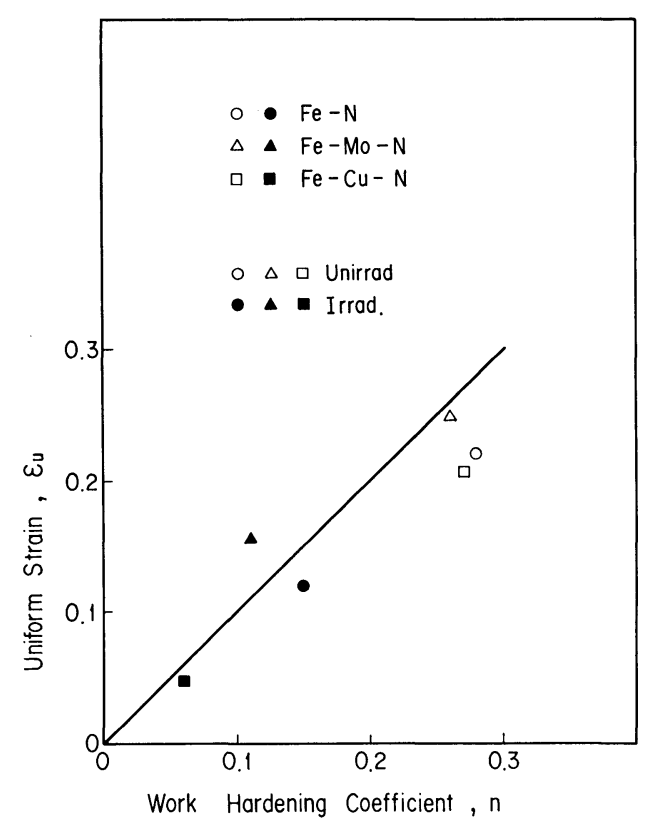

Fig. 1. The relation between observed $\varepsilon_{u}$ value and $n$ value.

\footnotetext{
* $\quad$ Received June 14, 1982 . C 1983 ISIJ

** Department of Metallurgy and Materials Science, The University of Tokyo, Hongo, Bunkyo-ku, Tokyo 113.

*** Tokai Research Establishment, Japan Atomic Energy Research Institute, Tokai-mura, Naka-gun, Ibaraki 319-11.
} 
where, $C:$ coefficient of nearly 1

$D$ : coefficient for post-uniform strain.

Figure 3 shows the relation between frictional stress

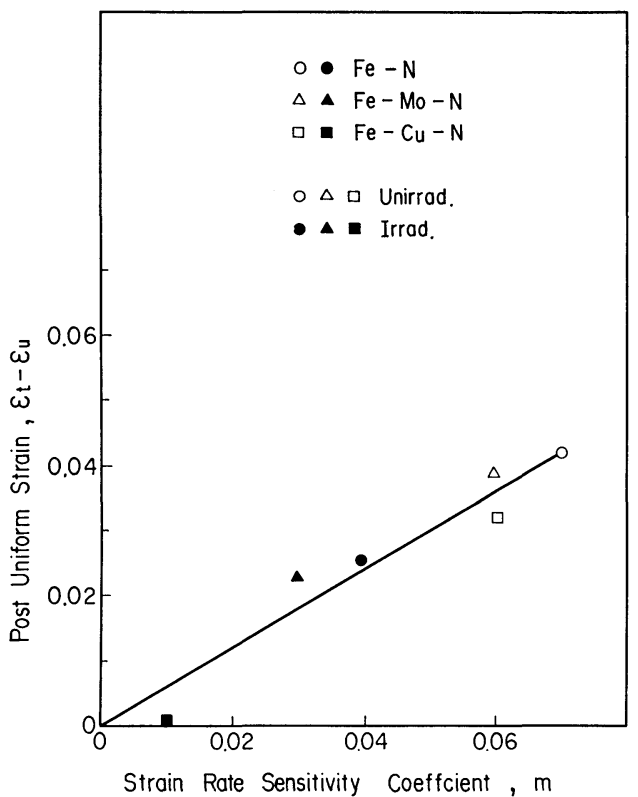

Fig. 2. The relation between local necking strain and $m$ value.
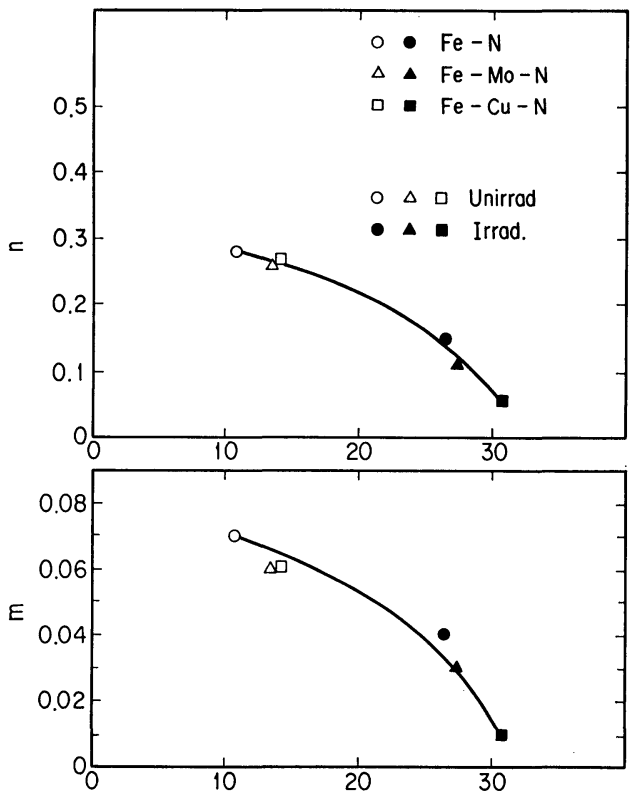

Frictional Stress, $\sigma_{\mathrm{i}}\left(\mathrm{kg} / \mathrm{mm}^{2}\right)$

Fig. 3. The observed $n$ value and $m$ value vs. frictional stress $\sigma_{i}$. $\sigma_{i}\left(=\sigma_{0}+\sigma_{\phi}\right)$ obtained by Rosenfield's method ${ }^{7)}$ and $n$ and $m$ values. After irradiation, both $n$ and $m$ values decrease with increasing the frictional stress. The reason why $n$ and $m$ values decrease with increasing the frictional stress can be understood as the following. When we denote static stress as $\sigma_{s}$ and dynamic stress as $\sigma_{d}$, the total stress can be expressed as the next equation.

$$
\sigma=\sigma_{d}+\sigma_{s}
$$

In the above equation, $\sigma_{d}$ and $\sigma_{s}$ can be expressed as follows.

$$
\begin{aligned}
\sigma_{d} & =\beta \dot{\varepsilon}^{m^{\prime}} \\
\sigma_{s} & =\sigma_{0}+\sigma_{\phi}+\alpha^{\prime} \varepsilon^{n^{\prime}}
\end{aligned}
$$

where, $\beta, m^{\prime}$ : materials parameter

$\sigma_{0}:$ frictional force

$\sigma_{\phi}:$ irradiation hardening

$\alpha^{\prime} \varepsilon^{n^{\prime}}:$ strain hardening in which $\alpha^{\prime}$ and $n^{\prime}$ are materials parameter.

Then from the Eqs. (2), (7) to (9), the next equation can be deduced approximately,

$$
\begin{aligned}
n & =\frac{d \log \sigma}{d \log \varepsilon} \\
& =n^{\prime}\left(1-\frac{\sigma_{0}+\sigma_{\phi}+\sigma_{d}}{\sigma}\right)=\frac{n^{\prime} \alpha^{\prime} \varepsilon^{n^{\prime}}}{\sigma}
\end{aligned}
$$

From the Eqs. (4), (7) to (9), the next equation follows approximately,

$$
\begin{aligned}
m & =\frac{d \log \sigma}{d \log \dot{\varepsilon}} \\
& =m^{\prime}\left(1-\frac{\sigma_{0}+\sigma_{\phi}+\alpha^{\prime} \varepsilon^{n^{\prime}}}{\sigma}\right)=\frac{m^{\prime} \beta \dot{\varepsilon}^{m^{\prime}}}{\sigma}
\end{aligned}
$$

In Eqs. (10) and (11), it is shown that the increase of $\sigma_{\phi}$ value makes $n$ or $m$ value smaller. The values of $n$ and $m$ are also related to values of $n^{\prime} \alpha^{\prime} \varepsilon^{n^{\prime}}$ and $m^{\prime} \beta \dot{\varepsilon}^{m^{\prime}}$ after irradiation.

Table 1 shows the each parameters in Eqs. (10) and (11). From this table the relation between $n^{\prime} \alpha^{\prime} \varepsilon^{n^{\prime}}$ and $m^{\prime} \beta \dot{\varepsilon}^{m^{\prime}}$ values and $\sigma_{i}$ can be shown in Fig. 4. This shows that the increase of $\sigma_{i}$, which is due to irradiation hardening, makes the decrease of $n^{\prime} \alpha^{\prime} \varepsilon^{n^{\prime}}$ and $m^{\prime} \beta \dot{\varepsilon}^{m^{\prime}}$. Therefore, from Eqs. (10) and (11) it is

\begin{tabular}{|c|c|c|c|c|c|c|c|c|c|c|c|}
\hline & & $\begin{array}{c}\sigma_{0} \\
(\mathrm{~kg} / \mathrm{mm}\end{array}$ & $\begin{array}{c}\sigma_{\phi} \\
\mathrm{g} / \mathrm{mm}\end{array}$ & $\begin{array}{c}\alpha^{\prime} \varepsilon^{n^{\prime}} \\
\mathrm{gg} / \mathrm{mm}\end{array}$ & $\begin{array}{l}\beta \dot{\varepsilon}^{m^{\prime}} \\
\left.\mathrm{g} / \mathrm{mm}^{2}\right)\end{array}$ & $n^{\prime}$ & $n_{\text {cal. }}$ & $n_{\text {obs. }}$ & $m^{\prime}$ & $m_{\text {cal. }}$ & $m_{\text {obs. }}$ \\
\hline \multirow{3}{*}{$\begin{array}{l}\text { Before } \\
\text { irradiation }\end{array}$} & $\mathrm{Fe}-\mathrm{N}$ & 10.7 & 0 & 15.9 & 2.3 & 0.66 & 0.36 & 0.28 & 0.32 & 0.03 & 0.07 \\
\hline & $\mathrm{Fe}-\mathrm{Mo}-\mathrm{N}$ & 13.3 & 0 & 16.2 & 2.7 & 0.59 & 0.30 & 0.26 & 0.34 & 0.03 & 0.06 \\
\hline & $\mathrm{Fe}-\mathrm{Cu}-\mathrm{N}$ & 14.0 & 0 & 12.9 & 1.0 & 0.57 & 0.26 & 0.27 & 0.42 & 0.02 & 0.06 \\
\hline \multirow{3}{*}{$\begin{array}{l}\text { After } \\
\text { irradiation }\end{array}$} & $\mathrm{Fe}-\mathrm{N}$ & 10.7 & 15.6 & 6.4 & 1.0 & 0.63 & 0.12 & 0.15 & 0.52 & 0.02 & 0.04 \\
\hline & $\mathrm{Fe}-\mathrm{Mo}-\mathrm{N}$ & 13.3 & 14.6 & 9.1 & 1.5 & 0.45 & 0.11 & 0.11 & 0.53 & 0.02 & 0.03 \\
\hline & $\mathrm{Fe}-\mathrm{Cu}-\mathrm{N}$ & 14.0 & 16.7 & 4.4 & 0.5 & 0.29 & 0.03 & 0.06 & 0.61 & 0.01 & 0.01 \\
\hline
\end{tabular}
clear that the decrease of $n$ and $m$ values is attributed to the irradiation hardening directly and the change of $n^{\prime} \alpha^{\prime} \varepsilon^{n^{\prime}}$ and $m^{\prime} \beta \dot{\varepsilon}^{m^{\prime}}$ indirectly.

Figure 5 shows the relation between irradiation hardening and the decrease of total ductility. The

Table 1. Materials parameters of iron and iron alloys. $\left(\varepsilon=\varepsilon_{\text {load max. }}\right)$ 

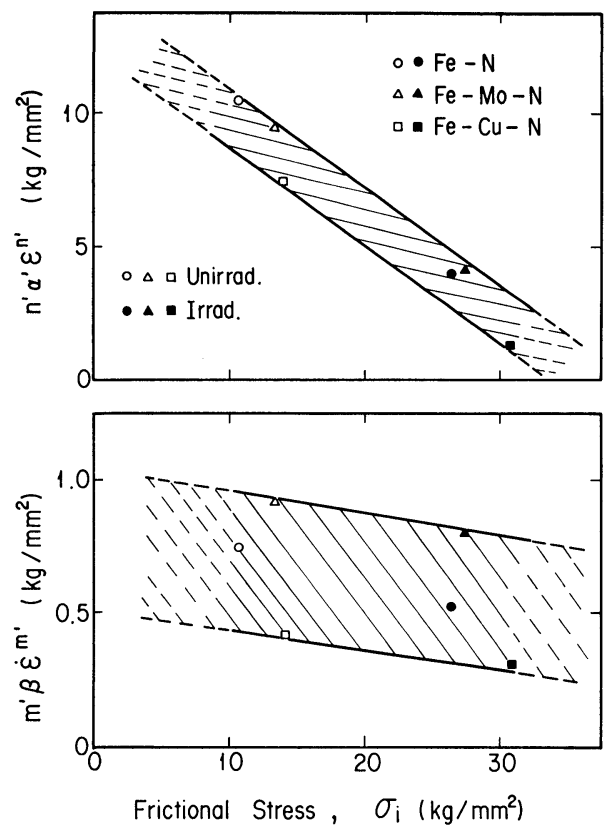

Fig. 4. The relation between $n^{\prime} \sigma^{\prime} \varepsilon^{n^{\prime}}$ and $m^{\prime} \beta \dot{\varepsilon}^{m^{\prime}}$ values and frictional stress $\sigma_{i}$.

ductility is strongly affected by irradiation hardening. In the irradiation hardening, the behavior of nitrogen atoms and vacancies complex is considered to be essential factor, and the yield stress increases with the square root of the total neutron dose. ${ }^{8)}$

Therefore, when we compare the results of $\mathrm{Fe}-\mathrm{N}$ or $\mathrm{Fe}-\mathrm{Mo}-\mathrm{N}$ with $\mathrm{Fe}-\mathrm{V}-\mathrm{N}$, ${ }^{4)}$ less nitrogen-vacancy complex defects may be formed, in the latter, due to stronger trapping effect of vanadium for nitrogen compared with molybdenum, ${ }^{5)}$ and less irradiation hardening and less the decrease of total ductility is observed. Futhermore, when we compare the results of $\mathrm{Fe}-\mathrm{N}$ and $\mathrm{Fe}-\mathrm{Cu}-\mathrm{N}$, other than nitrogen-vacancy complex defects, copper-vacancy complex defects ${ }^{9)}$ may be formed and more irradiation hardening and more the decrease of total ductility is observed in the

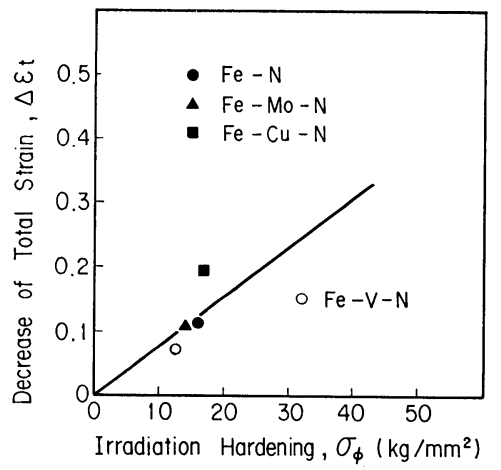

Fig. 5. The relation between irradiation hardening and the decrease of total strain.

latter.

After all, the way to keep post irradiation ductility is to suppress irradiation hardening through controlling of interstitial nitrogen atoms and substitutional atoms or impurities such as copper atoms.

\section{REFERENCES}

1) J. O. Stiegler and J. R. Weir, Jr.: Ductility, ASM, Ohio, (1967), 311.

2) L. E. Steele: Neutron Irradiation Embrittlement of Reactor Pressure Vessel Steels, Int'l Atomic Energy Agency, Vienna, (1975), 93.

3) J. Gittus: Irradiation Effects in Crystalline Solids, Applied Science Publishers, Ltd., London, (1978), 167.

4) N. Igata, R. R. Hasiguti and K. Watanabe: Proceedings of the Third International Conference on the Strength of Metals and Alloys, The Inst. Metals and ISI, Cambridge, (1973), 21.

5) N. Igata, K. Watanabe and S. Sato: ASTM, Spec. Tech. Pub., 529 (1973), 63.

6) N. Igata, H. Kayano and K. Watanabe: ASTM Spec. Tech. Publ., 570 (1975), 24.

7) A. R. Rosenfield: J. Inst. Metals, 91 (1962), 104.

8) S. B. McRickard: Phil. Mag., 18 (1968), 915.

9) F. A. Smidt, Jr. and H. E. Watson: Met. Trans., 3 (1972), 2065. 